\title{
Comparative morphometric study of the sigmoid sinus sulcus and the jugular foramen
}

\author{
Estudo morfométrico comparativo do sulco do seio sigmóideo e do forame jugular \\ Silvio Pereira Ramos-Junior ${ }^{1,2}$, Sebastião Natanael da Silva Gusmão3, Jair Leopoldo Raso ${ }^{1,4}$, \\ Arthur Adolfo Nicolato', Marcileia Santos', Isabela Maciel Caetano ${ }^{1}$
}

\begin{abstract}
Objective: To compare the right and left sides of the same skulls as far as the described landmarks are concerned, and establish the craniometric differences between them. Method: We carried out measurements in 50 adult dry human skulls comparing both sides. Results: The sigmoid sinus width at the sinodural angle level was larger on the right side in $78 \%$ of the cases and at the level of the digastric notch in $72 \%$. The jugular foramen width was also larger on the right side in $84 \%$ of the cases. The sigmoid sinus distance at the level of the digastric notch was larger on the right side in $64 \%$ of the cases, and the sigmoid sinus distance at the level of the digastric notch to the jugular foramen was larger on the right side in $70 \%$ of the cases. Conclusion: Significant craniometric differences were found between both sides of the same skulls.
\end{abstract}

Keywords: skull base, posterior fossa, jugular foramen, craniometric points, sigmoid sinus.

RESUMO

Objetivo: Comparar os lados direito e esquerdo no mesmo crânio nos pontos referenciais descritos e definir as diferenças craniométricas entre ambos. Método: Realizamos mensurações em 50 crânios secos de humanos adultos comparando os lados direito e esquerdo. Resultados: Como resultado, obtivemos as medidas da largura do seio sigmóideo na altura do ângulo sinodural maiores no lado direito em $78 \%$ dos casos e na altura do ponto digástrico em $72 \%$. A largura do forame jugular foi também maior no lado direito em $84 \%$ dos casos. A distância do seio sigmóideo na altura do ângulo sinodural até a altura do ponto digástrico foi maior do lado direito em 64\% dos casos, e a distância do seio sigmóideo na altura do ponto digástrico até o forame jugular foi maior do lado direito em $70 \%$ dos casos. Conclusão: Diferenças craniométricas significativas foram encontradas entre os dois lados do crânio.

Palavras-chave: base do crânio, fossa posterior, forame jugular, pontos craniométricos, seio sigmóideo.

The jugular foramen, with its internal and neighboring vital structures, represents a major challenging the treatment of lesions in that region. Knowledge about the anatomy and the microsurgical techniques, associated with knowing the landmarks on the internal and external surfaces of this region mitigate morbidity and improve the prognoses of surgical interventions, preserving nervous and vascular structures.

In this paper we report a comparative study of the sigmoid sinus and the jugular foramen using the following structures as key landmarks: the sigmoid sinus sulcus the transition point between the sigmoid sinus sulcus and the transverse sinus (sigmoid/transverse sinus) and the digastric notch in both sides of the same skull. With such measures we tried to create reference points to help surgeons approach the sigmoid sinus region.

To establish reference values between the right and left sides for the sigmoid sinus sulcus and the jugular foramen using the transverse/sigmoid sinuses junction point and the digastric notch as landmarks.

Assess whether or not there are differences in the values measured between the left and right sides of the same skull.

\footnotetext{
${ }^{1}$ Universidade Federal de Minas Gerais, Belo Horizonte MG, Brazil;

${ }^{2}$ Departamento de Neurocirurgia, Santa Casa de Caridade de Diamantina, Diamantina MG, Brazil;

${ }^{3}$ Hospital das Clínicas, Universidade Federal de Minas Gerais, Belo Horizonte MG, Brazil;

${ }^{4}$ Instituto Mineiro de Neurocirurgia, Belo Horizonte MG, Brazil.

Correspondence: Isabela Maciel Caetano; Alameda das Amendoeiras, 235 Ouro Velho; 34000-000 Nova Lima MG, Brasil;

E-mail: isabelamcaetano@gmail.com

Conflict of interest: There is no conflict of interest to declare.

Received 13 February 2014; Received in final form 07 June 2014; Accepted 27 June 2014
} 


\section{METHOD}

We assessed 50 dry human skulls belonging to the Anatomy Center of the Federal University of the Jequitinhonha and Mucuri River Valleys (11 skulls), from the Surgical Anatomy Laboratory of the Medical School of the Federal University of Minas Gerais (7 skulls) and from the Department of Morphology of the Institute of Biological Sciences of the Federal University of Minas Gerais (32 skulls).

On the outer surface of each side of the skulls we identified the digastric notch, the asterion, the occipitomastoid suture, the jugular notch, the stylomastoid foramen and the jugular foramen.

On the skull's inner surface, we identified the sigmoid sinus sulcus, the sinodural angle, the digastric notch and the jugular foramen.

In each skull side we measured the sigmoid sinus sulcus width and length, and the jugular foramen width on the following sites:

- Sigmoid sinus sulcus width at the sinodural angle;

- Sigmoid sinus sulcus distance from the sinodural angle all the way to its anterior curvature at the digastric notch level;

- Sigmoid sinus sulcus width near the digastric notch;

- Sigmoid sinus distance from the digastric notch level all the way to the jugular foramen;

- Jugular foramen width, measured on the infero-external skull surface (Table 1).

The distances and widths were all measured bilaterally in 50 dry adult human skulls, without gender separation. The measures were carried out using a digital pachymeter. We did three measurements for each distance and width, and the mean value was considered the checked value for statistical analysis purposes.

In order to define the digastric notch counterpart on the internal skull surface we used skull transillumination with LASER. We used the LASER source mounted on a pen/ pointer. The pen was placed on the digastric notch and,

Table 1. List of Acronyms used for the variables.

\begin{tabular}{lc}
\hline Full name of the measure & Acronym \\
\hline Left side width - sinodural angle & ASDLE \\
Right side width - sinodural angle & ASDLD \\
Left side distance - sinodural angle-digastric notch & ASDDE \\
Right side distance - sinudural angle-digastric notch & ASDDD \\
Left side width - digastric notch & PDLE \\
Right side width - digastric notch & PDLD \\
Left side distance - digastric notch jugular foramen & PDFJDE \\
Right side distance - digastric notch jugular foramen & PDFJDD \\
Left side widht - jugular foramen & FJLE \\
Right side width - jugular foramen & FJLD \\
\hline
\end{tabular}

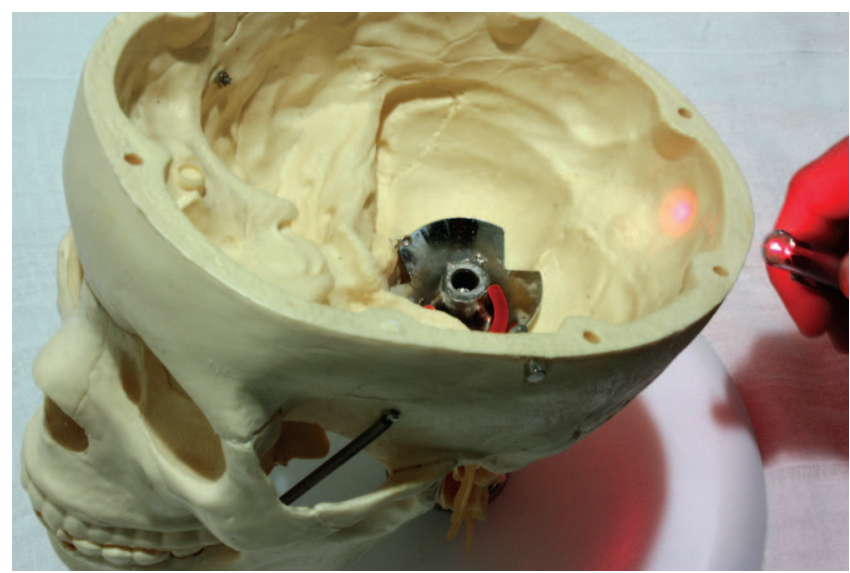

Figure. Skull transillumination with a LASER to define the digastric notch correspondent on the skull's inner surface.

by means of transillumination with LASER, the corresponding point on the inner skull surface was established and marked with a pencil (Figure).

When the skull thickness did not allow for LASER transillumination ( 8 skulls), the correspondent to the digastric notch on the skull's inner surface was defined using the caliper, with its tips making a 90 degree angle-one of the tips was placed on the digastric notch and the other was on the correspondent point on the inner surface, we marked this point with a pencil so as to serve as a correspondent for the proposed measurements.

\section{Sample calculation}

The present study sample size was defined assuming a normal distribution for each one of the quantitative variables.

In order to study two dependent groups, right and left sides of the same skull, we chose the paired t-test for analysis. The sample calculation depended on the mean and standard deviation, since we still did not have these figures, we used figures established in the literature such as "small" (0.3), "medium" (0.7) or "large" (1.1).

Considering the mean effect and the minimum power above $90 \%$, we decided for 50 pairs of observations on the right and left sides of the skull.

We made an exploratory analysis of the total sample, encompassing 50 dry adult skulls. We used descriptive measures (mean, standard deviation, minimum and maximum) for the variables. The descriptive analysis aimed at establishing general reference values by side: right and left, for the distances and angles measured. We tested the normality of the data in order to decide on which test should be employed. We found a normal distribution in all the measures, except for the FJLD. For the measures with normal distribution we utilized a parametric test. For the FJLD measurement, we used a non-parametric test. In order to assess the differences between the mean values from the 
right and left sides we used the paired t-test. We studied the two sides of the same skull. When the distribution was not normal, we used the Wilcoxon test. In all the statistical tests used, we considered $5 \%$ as the level of significance. Thus, we considered statistically significant associations those which $\mathrm{p}$ value was lower than 0.05. The analyses were carried out using the SPSS statistical software package, version 8.0.

Because we made three measurements for each data, we utilized the intraclass correlation coefficient to test the intraexaminer reliability. The closer it was from 1, the more accurate the measurement. We found coefficients very close to 1 , showing that the measurements were compliant.

The hypothesis test was as follows: $H_{o}: \mu_{d}=\mu_{e}$ versus $\mathrm{H}_{1}: \mu_{\mathrm{d}} \neq \mu_{\mathrm{e}}$.

\section{RESULTS}

We used the mean values of three measurements for the following comparisons (Table 2).

The results depicted on Table 2 show that in our sample the right-side measures were larger than those made on the left side. We carried out a study to check and see whether such difference was statistically significant.

For a Gaussian distribution of the mean $\mu$ and the standard deviation $\sigma$, intervals $(\mu-\sigma ; \mu+\sigma),(\mu-2 \sigma ; \mu+2 \sigma)$ and $(\mu-3 \sigma ; \mu+3 \sigma)$ represent $68.3 \%, 95.4 \%$ and $99.7 \%$ of the distribution, respectively. For samples larger than 30 it is expected that $\mu$ would be closer to the sample mean, and $\sigma$ would be closer to the sample's standard deviation.

We noticed an indication that the variables do have a Gaussian distribution, except for the FJLD variable, which presented a significant difference in the first percentage value.

We also noticed that the mean values of all the variables were higher on the right side. We ran the hypothesis test to check whether or not this difference was statistically significant. We used the t-test for two paired samples of the variables with a Gaussian distribution; for the FJLD variable we used the Wilcoxon non-parametric test for paired data. We considered $5 \%$ as significant.

The results from the tests had the $\mathrm{p}$ values presented on Table 3:

Considering the $\mathrm{p}$ value (below 0.05 for all the left-right pairs), we must reject the null hypothesis of equality of the

Table 2. Comparing the Right/Left Sample Ratio.

\begin{tabular}{lc}
\hline Right/Left Comparison & Percentage \\
\hline ASDLD>ASDLE & $78 \%$ \\
ASDDD>ASDDE & $62 \%$ \\
PDLD $>$ PDLE & $74 \%$ \\
PDFJDD $>$ PDFJDE & $70 \%$ \\
FJLD>FJLE & $84 \%$ \\
\hline
\end{tabular}

mean values. Thus, we conclude that the mean right-left measures'differences were significant for all the variables in the study.

\section{DISCUSSION}

The identification of superficial anatomical landmarks, known as craniometric points, which represent projections of vascular and neural structures on the skull enables us to define landmarks for cranial accesses. Detailed knowledge about the anatomical relations of craniometric points is paramount for neurosurgeons, especially when approaching the skull base. Moving from one landmark to another, the neurosurgeon may broaden craniotomies to better expose the area to be operated, identifying and preserving vascular and neural structures, reducing the morbidity directly associated with the surgical approach.

With today's technological evolution, many instruments have been added to neurosurgery, such as neuronavigation and intraoperative monitoring of cranial nerve function. The correct use and interpretation of the information supplied by these instruments is only possible when the surgeon has full anatomical knowledge.

There are many craniometric points described for temporal bone approaches, most of them associated with the cranial sutures, which represent natural landmarks.

The asterion has been studied by different authors as the landmark used for a precise finding of the transverse sinus and the transverse/sigmoid sinus transition. These studies were carried out with the aim of guiding surgeons as to the site for trephinations in lateral suboccipital approaches ${ }^{1,2,3,4,5,6,7}$. The asterion was not very useful as a landmark because of its anatomical variability and it is not always promptly identifiable . $^{8}$

This variation in the preference for a trephination site in this small anatomical area involves two aspects: a potential risk of damaging the venous sinuses and the limited bone opening.

Few studies instruct the surgeon on doing the trephinations using the lower limits of the sigmoid sinus as landmarks. One of them used the upper nuchal line as a landmark, making the trephination immediately below it and posterior to the axis established by the mastoid tip

Table 3. $p$ value of the tests.

\begin{tabular}{lc}
\hline Compared pairs & p value \\
\hline ASDLE-ASDLD & 0.000 \\
ASDDE-ASDDD & 0.048 \\
PDLE-PDLD & 0.001 \\
PDFJDE-PDFJDD & 0.006 \\
FJLE-FJLD & 0.000 \\
\hline
\end{tabular}


and the junction of the squamous and parietomastoid sutures ${ }^{7}$. Other study used the occipitomastoid suture at the mastoid incisure level, considering that a proper place to make the trephination and expose the posterior and inferior margins of the sigmoid sinus ${ }^{2}$.

In anatomical dissections aiming at illustrating the transpetrosal approach with partial labyrinthectomy, was noticed that the sigmoid sinus curved anteriorly towards the jugular bulb $^{9}$. This curvature was located near the top of the mastoid incisure. Although easily identifiable in dry skulls, the cranial sutures may be difficult to pinpoint during surgical procedures and in anatomical dissections. In a study were dissected heads and properly pinpointed the sutures in about $60 \%$ of the cases investigated ${ }^{8}$. In that same study, they did not find the occipitomastoid suture in 14 of the 24 sides studied.

A study described a new craniometric point, associating it with the anterior curve of the sigmoid sinus ${ }^{10}$. This landmark - called digastric notch, was defined as the point located immediately posterior to the mastoid incisure in dry skulls, or the notch immediately superior to the posterior belly of the digastric muscle in dissections and surgical procedures. The digastric notch is projected on the sigmoid sinus sulcus on the internal skull surface in $49.6 \%$ of the cases on the right side and in $29.9 \%$ on the left. When not coinciding with the sigmoid sinus sulcus, this notch was located at $3.10 \mathrm{~mm}$ higher than average (SD $3.11 \mathrm{~mm}$ ), being shorter on the right side, thus showing a lack of symmetry between skull sides.

This notch was used as a landmark, making the trephination to gain access to the posterior fossa at $1 \mathrm{~cm}$ medial to it, to avoid exposing the sigmoid sinus ${ }^{8}$. This study was carried out in 10 dry skulls and in 12 heads injected with colored silicone in the arteries and veins, they described that the mastoid incisure completely covered the sigmoid sinus in $85 \%$ of the specimens.

Very few papers assessed skull differences reflecting size differences in vascular structures such as the sigmoid sinus. Based on one of them we may conclude that the sigmoid sinus is larger on the right $\operatorname{side}^{10}$. In a study involving 263 digital brain angiographies with bone subtraction, was found symmetric sigmoid sinuses in $49 \%$ of the cases ${ }^{11}$. In about $36 \%$ of the cases, the right-side sigmoid sinus was dominant, or the only one present.

It was to be expected that anatomical studies would find differences in the distance measures involving anatomical landmarks, such as the sigmoid sinus sulcus, between both sides of the skull. However, in two studies there was no difference between skull sides vis-à-vis the measures carried out ${ }^{2,3}$. It was not compared the sides in their craniometric measurements ${ }^{8}$. Considering measurements between the mastoid tip and the lateral margin of the jugular foramen, the lateral margin of the stylomastoid foramen and the lateral margin of the occipital condyle, there were no sidewise differences among the 25 skulls investigated ${ }^{12}$.

When the number of skulls studied is higher, one usually finds differences between the two sides. In two studies involving 100 dry skulls ${ }^{6}$ and 84 skulls $^{7}$, were found differences between the right and left sides vis-à-vis the asterion and the transverse sinus.

A group studied the jugular foramen microanatomy in ten cadavers $^{13}$. The right-side jugular foramen was wider than the left one in $70 \%$ of the cases. In this paper, with 5 times more specimens, the difference increased to $84 \%$.

In the present study we investigated the entire extension of the sigmoid sinus and jugular foramen, and we measured the sulcus width near the point corresponding to the sinodural angle, which marks the beginning of the sigmoid sinus, near the digastric notch, corresponding to its anterior curvature and jugular foramen width. We also measured the sigmoid sinus sulcus distance from the sinodural angle all the way to its anterior curvature at the level of the digastric notch, and from this point all the way to the jugular foramen.

The sigmoid sinus width values at the level of the sinodural angle are larger on the right side in $78 \%$ of the cases and at the digastric notch level in $72 \%$. The jugular foramen width was also higher on the right side in $84 \%$ of the cases. The sigmoid sinus distance at the level of the sinodural angle all the way to the digastric notch was higher in the right side in $64 \%$ of the cases, and the sigmoid sinus distance from the digastric notch to the jugular foramen was higher in the right side in $70 \%$ of the cases.

Our findings confirm the asymmetry between skull sides. The comparative measures vis-à-vis the jugular foramen width and the sigmoid sinus sulcus, in two reference points show that it is higher on the right side, thus contributing with one more piece of information for the surgical planning of lesions involving this region of difficult approach and eloquent structures.

In conclusion the craniometric measurements carried out in this study and their statistical analyses allow us to reach the following conclusions:

1) In most of the cases, the sigmoid sinus sulcus width at the transverse/sigmoid sinuses transition point, the sigmoid sinus sulcus distance from the transverse/sigmoid sinuses transition level all the way to its anterior curvature at the level of the digastric notch, the sigmoid sinus sulcus width near the digastric notch, the sigmoid sinus sulcus distance from the digastric notch all the way to the jugular foramen are larger on the right side of the same skull;

2) The jugular foramen width is larger on the right side in most of the skulls. 
1. Ribas GC. Estudo das relações topográficas das suturas lambdóide, de occipitomastóidea e parietomastóidea com os seios transverso e sigmoide etrepanações da região. São Paulo: Tese de Doutoramento, Faculdade de Medicina da Universidade de São Paulo, 1991.

2. Ribas GC, Rhoton AL, Cruz OR, Peace D. Temporo-parieto-occipital burr hole sites study and systematized approaches proposal. In: Samii M, (edit.) Skull Base Surgery: First Int Skull Base Congr. Basel, Karger,1994:723-730.

3. Ribas GC, Rhoton AL, Cruz OR, Peace D. Suboccipital burr holes and craniectomies. Neurosurg Focus 2005;19:E1.

4. Gusmão S, Silveira, RL, Arantes, A. Pontos referenciais nos acessos cranianos. ArqNeuropsiquiatr. 2003;61:303-308.

5. Day JD, Kellogg JX, Tschabitscher M, Fukushima T. Surface and superficial surgical anatomy of the posterolateral cranial base: significance for surgical planning and approach. Neurosurgery 1996;38:1079-1083.

6. Day JD, Tschabitscher M. Anatomic position of the Asterion. Neurosurgery 1998;42:198-199.
7. Bozbuga M, Boran BO, Sahinoglu K. Surface anatomy of the posterolateral cranium regarding the localization of the initial burrhole for a retrosigmoid approach. Neurosurgery 2006;29:61-63.

8. Avci E, Kocaohullar Y, Fossett D, Caputy A. Lateral posterior fossa venous sinus relationships to surfacelandmarks. Surg Neurol 2003;59:392-397.

9. Sekhar LN, Schessel DA, Bucur, SD, Raso JL, Wright DC. Partial Labyrinthectomy petrous apicectomy approach to neoplastic and vascular lesions of the petroclival area. Neurosurgery. 1999;44:537-552.

10. Raso J, Gusmão S, A new landmark for finding the sigmoid sinus in suboccipital craniotomies. Neurosurgery 2011;68(Suppl):1-6.

11. Shima T, Okita S, Okada Y, Nishida M, Yamane K, Hatayama T. Anatomical dominance of venous sinuses and jugular vein examined by intravenous digital subtraction angiography. In: Hakuba A (Ed). Surgery of the Intracranial Venous System. 1996.

12. Tedeschi H, Rhoton Jr, AL. Lateral approaches to the petroclival region. SurgNeurol 1994;41:180-216.

13. Ayeni SA, Ohata K, Tanaka K, Hakuba A. The microsurgical anatomy of the jugular foramen. J Neurosurg 1995;83:903-909. 